\title{
PROFESSORES E ESTUDANTES PRODUZINDO 0 CONHECIMENTO HISTÓRICO - reflexões teóricas e práticas sobre a aula-oficina
}

\author{
Jeferson José Gevigier*
}

\begin{abstract}
RESUMO: No presente artigo, apresentamos reflexões resultantes de nossa pesquisa no ProfHistória que fundamentam a importância do uso de fontes históricas em sala de aula e que estão disponíveis no site que produzimos para divulgação de nossas propostas. Por isso, acreditamos necessária a reflexão teórico-metodológica sobre a prática do ensino de história a partir da estrutura da aula-oficina e o apontamento de possibilidades práticas deste modelo, evidenciando a associação entre pesquisa e ensino de história. Nossas reflexões passam pelas diferentes etapas da aula-oficina, abordando tanto os aspectos teóricos de cada uma delas quanto sugestões de trabalho prático em sala, tendo em vista a autonomia acadêmica dos professores.
\end{abstract}

PALAVRAS-CHAVE: Ensino de história; Aula-oficina; Sequências didáticas; Conhecimento histórico.

\section{Teachers and students producing historical knowledge: theoretical and practical reflections on the workshop-class}

\begin{abstract}
In this a paper, we present reflections resulting from our research at ProfHistoria that substantiate the importance of the use of historical sources in the whorkshop-class and which are available on the website we produced for the dissemination of our proposals. Therefore, we believe it is necessary to reflect on the theoretical and methodological practice of history teaching based on the structure of the workshop-class and to point out the practical possibilities of this model, highlighting the association between research and history teaching. Our reflections go through the different stages of the whorkshop-class, approaching both the theoretical aspects of each one of them and the suggestions of practical work in the classroom, having in mind the academic autonomy of the teachers. KEYWORDS: history teaching; workshop-class; didactic sequences; historical knowledge.
\end{abstract}

\section{Profesores y alumnos produciendo conocimiento histórico: reflexiones teóricas y prácticas sobre la clase-taller}

RESUMEN: En este artículo, presentamos las reflexiones resultantes de nuestra investigación en ProfHistoria que avalan la importancia del uso de las fuentes históricas en el aula y que están disponibles en el sitio web que elaboramos para la difusión de nuestras propuestas. Por ello, creemos necesario reflexionar sobre la práctica teórica y metodológica de la enseñanza de la historia a partir de la estructura de la clase-taller y señalar las posibilidades prácticas de este modelo, destacando la asociación entre investigación y enseñanza de la historia. Nuestras reflexiones recorren las diferentes etapas de la clase-taller, abordando tanto los aspectos teóricos de cada una de ellas como las sugerencias de trabajo práctico en el aula, teniendo en cuenta la autonomía académica de los profesores.

PALABRAS CLAVE: enseñanza de la historia; clase-taller; secuencias didácticas; conocimiento histórico.

\footnotetext{
*Mestre em Ensino de História pelo ProfHistória pela Universidade Estadual de Maringá. Atualmente cursa disciplinas especiais no curso de Doutorado em História pela mesma instituição e atua como diretor no Colégio Estadual Cívico-Militar Francisco Ferreira Bastos. Contato: Rua Teu-teu, 275, Jd. Aeroporto, CEP: 86702-030, Arapongas-PR, Brasil. Email: jgevigier@ hotmail.com. ORCID: https://orcid.org/0000-0001-8071-5062
} 
O presente artigo é um recorte de nossa pesquisa no âmbito do Mestrado Profissional em Ensino de História, o que resultou em um produto educacional voltado para o ensino de história ${ }^{1}$. O objetivo global de nossa pesquisa foi a elaboração de propostas de sequências didáticas, refletindo sobre a práxis docente que garantisse a pesquisa historiográfica e o ensino de história, ou seja, o trabalho docente focado na produção do conhecimento histórico por professores e estudantes a partir da análise e interpretação de fontes históricas e na produção narrativa historicizada. Portanto, nosso principal objetivo com este ensaio é a reflexão sobre os aspectos teóricos e práticos do ensino de história a partir de uma preocupação que se fez presente durante o desenvolvimento de nossa pesquisa: como elaborar propostas de sequência didática que, embasada em preceitos teórico-metodológicos e na pesquisa histórica, tendo como objeto um conteúdo substantivo determinado, indicando o trabalho com conceitos de segunda ordem necessários para o desenvolvimento da literacia histórica, não recaísse em um formato simplista ao estilo "passo a passo".

Essa preocupação é assim expressa pela professora Marcia Elisa Teté Ramos ao recorrer à Isabel Barca: "Enquanto que a pergunta-base nas pesquisas mais tradicionais sobre ensino de história centravam em como motivar alunos [...] a problemática de algumas vertentes, por exemplo, da Educação Histórica, corre no sentido de responder sobre como os alunos compreendem a história, [...] não se centrando nos "formalismos e recursos da aula". 2

Outro aspecto dessa preocupação diz respeito às diversas realidades presentes nas escolas públicas com as quais convivemos cotidianamente. Situações de fragilidade social, políticas públicas contraditórias que não contribuem para o trabalho docente, más condições de infraestrutura dos prédios escolares ou obras em períodos de aulas, dificuldade em desenvolver atividades remotas/online visto que o acesso aos equipamentos e à internet não é universalizado. Não temos a pretensão de apresentar soluções para todos os desafios tampouco de ensinar a professores, nossos pares, como dar aula, mas temos como objetivo refletir sobre a prática do ensino de história, em meio às diferentes situações adversas e buscando subsídios conceituais nas formas como o ensino de história tem sido desenvolvido nos últimos anos.

Segundo Isabel Barca ${ }^{3}$ são pressupostos da Educação Histórica: a inter-relação entre teoria e prática, desenvolvendo o ensino de história com base em investigações e propostas testadas empiricamente. Assim, os conteúdos substantivos selecionados por nós ou por outros professores, podem se tornar objetos de reflexão sobre formas de se ensinar 
história, a partir da pesquisa em sala de aula pelos estudantes e pelo professor, criando condições para que o conhecimento histórico, produzido por eles, possa contribuir para que os sentidos atribuídos pelos alunos à realidade sejam instrumentalizados e desenvolvidos. $\mathrm{O}$ conhecimento, portanto, é uma construção concomitantemente acadêmica e escolar, pois “[...] quando se diz conhecimento histórico científico, se fala em pesquisa, e esta é o fundamento da historiografia consistente, mas possível de ser transposta para a sala de aula, como forma de 'enriquecimento' das concepções históricas que formam o senso comum". 4

Nossa reflexão tem como objetivo o desenvolvimento e o enriquecimento das concepções históricas dos estudantes a partir do trabalho nas aulas, o que em nosso entender, é uma das funções do ensino de história. Segundo Albuquerque Júnior (2012), essa função é a desnaturalização do presente, refletindo acerca do passado sobre todos os aspectos da vida comum, da política, da sociedade e da cultura. É função do ensino de história a busca pelos significados perdidos no tempo e banalizados pelo uso cotidiano, dos quais alguns podem, inclusive, ser objetos de afirmação de poder ou de perpetuação de desigualdades. Ao compreender o passado como uma construção, os estudantes terão condições de perceber que o nosso presente também está em construção (devir), que pessoas do passado são diferentes, mas não inferiores (alteridade), que as sociedades passadas buscavam se organizar da melhor maneira que podiam, mesmo cometendo erros. Esses erros podem ser explicados, embora não necessariamente aceitos, a partir da pesquisa histórica (empatia). Os estudantes podem compreender ainda que existem diferentes formas de se viver, diferentes maneiras de se resolver conflitos, diferentes formas de se vestir e de se alimentar, existem ideias, costumes e valores diferentes dos nossos (aprendizagem da tolerância) ${ }^{5}$.

Com base nessas reflexões, podemos iniciar as considerações acerca dos conceitos que possibilitem práticas docentes fundamentadas, nas quais o professor reflita sobre o modelo de aula que irá optar e sobre os pressupostos teórico-metodológicos e epistemológicos que a embasam, o que garantiria que o conhecimento produzido em sala, por ele e pelos alunos, tenha estatuto equivalente à produção historiográfica acadêmica. ${ }^{6} \mathrm{~A}$ ideia de que o conhecimento produzido academicamente e o produzido no processo de ensino possuem estatutos equivalentes, dadas as diferenças procedimentais, tem base nos estudos de Jörn Rüsen quando elaborou sua matriz disciplinar. A matriz apresenta princípios "que fundamentam a construção do conhecimento histórico, sob a concepção de que História escrita e ensinada são campos diferentes, mas não excludentes e ao mesmo tempo correlativos". Os processos de aprendizagem 
histórica ocorrem em diversos contextos da vida concreta, sendo a escola apenas um deles e não o mais popular. Isso significa que os estudantes "já trazem para a escola um conjunto de saberes apreendidos na sociedade, uma série de associações obtidas por intermédio da memória coletiva/cultura histórica". ${ }^{7} \mathrm{O}$ ensino de história, portanto, está conectado à teoria da história no sentido em que ambos operam processos da consciência histórica.

Algumas pesquisas empíricas realizadas em vários contextos, países e com abordagens diferentes sugerem que a produção do conhecimento em sala necessita do envolvimento dos estudantes com o próprio conhecimento. Uma dessas pesquisas, realizada por Cerri, com base em dados quantitativos, apresentou uma conclusão neste sentido:

A combinação de resultados [apresentados em sua pesquisa] sugere que uma estratégia de ensino e aprendizagem potencialmente positiva para conseguir atenção e engajamento dos estudantes passa por construir conhecimentos novos, no sentido de articular a história da família do aluno com processos históricos do Brasil recente, bem como da história mundial. Assim pode-se promover, pelo menos em parte, a aproximação entre o conhecimento histórico escolar e a experiência histórica mais próxima do aluno, através da memória e dos documentos. Apesar de esta ser uma estratégia comumente usada nas séries iniciais e nos primeiros contatos com a disciplina de História no $6^{\circ}$ ano do Ensino Fundamental, não é uma estratégia disseminada no ensino da história contemporânea e do ensino do Brasil recente, que ocorre em anos mais avançados da Educação Básica. A pesquisa mostrou, em suma, que tal interesse permanece até o final da Educação Básica, e aproveitá-lo parece uma das chaves para um ensino e uma aprendizagem mais significativos. ${ }^{8}$

Em nossa pesquisa, portanto, foram importantes as reflexões sobre modelos de ensino que garantam o interesse e a participação dos estudantes no processo de construção do conhecimento, o que só é possível caso a história ensinada se relacione de alguma forma com a história vivida.

Não são recentes as discussões acerca de modelos de aula sistematizados de acordo com sua lógica, métodos, avaliação e efeitos sociais de cada paradigma. Modelos tradicionais, não diretivos e democráticos são sistematizados e experimentados há décadas. Dentre estes modelos, Isabel Barca desenvolveu o conceito de Aula-Oficina em contraposição aos modelos que ela chama de aula-conferência e aula-colóquio. Segundo ela, no modelo de aula-conferência, marcado pelo paradigma tradicional, o professor detém o conhecimento verdadeiro a ser transmitido ao aluno que, por sua vez, não sabe, não pensa e deve reproduzir a mensagem como um receptáculo, por meio de testes escritos. Ainda segundo Barca, por mais que já se tenha consolidado um consenso de que este modelo não seja pedagogicamente correto, ele ainda é amplamente praticado. ${ }^{9}$

O modelo de aula-colóquio, dentro de um paradigma de tendência democrática, 
se preocupa com o planejamento e a organização das ações pedagógicas para além dos conteúdos. As aulas são centradas na criatividade de recursos e estratégias, nas quais "o saber pode ser problematizado e partilhado, mas a atenção continua a centrar-se na atividade do professor [...]. O pressuposto de que o conhecimento deve ser construído na aula pelos alunos é firmado como mera retórica [...]"10. Em essência, por mais que a preocupação com a inovação do ensino esteja presente, o protagonismo não está na produção do conhecimento, mas na reprodução das informações que, quando muito, adquirem uma linguagem mais palatável e agradável.

Quando o professor assume o papel de investigador social e pesquisador histórico, o estudante se torna o agente do conhecimento. $\mathrm{O}$ professor passa a investigar a realidade dos estudantes. Os conhecimentos tácitos trazidos por estes são a matéria prima para o trabalho daquele que não mais exerce o papel de arauto do conhecimento, mas de organizador das atividades problematizadoras que serão trabalhadas pelos estudantes num processo de reconhecimento e análise das ideias prévias e experiências.

A partir da relação entre história ciência e vida prática, o processo de ensinar história construindo o conhecimento histórico pode ser organizado em cinco etapas constitutivas: Interesses, Ideias, Métodos, Apresentação e Funções. ${ }^{11}$ Esta é a síntese da matriz disciplinar de Rüsen, a qual, quando transposta para o ensino de história constitui os princípios do modelo de Aula-Oficina, possibilitando a progressão gradual do conhecimento histórico e desenvolvendo as competências históricas essenciais a qualquer pessoa.

\section{AULA-OFICINA}

No trecho acima, apresentamos uma síntese das características, objetivos e métodos da Aula-Oficina que, nas palavras de Isabel Barca, pode ser descrita com a seguinte estrutura:

1. Recolha inicial de dados sobre as ideias prévias dos alunos acerca de um conceito substantivo, selecionado dentro de uma determinada unidade em estudo.

2. Análise das ideias prévias dos alunos segundo um modelo (simplificado) de progressão conceptual: categorização das ideias de alunos desde ideias incoerentes e alternativas até às relativamente válidas.

3. Desenho, planeamento e implementação de uma unidade temática tendo em conta um refinamento progressivo das ideias históricas dos alunos previamente diagnosticadas.

4. Recolha de dados sobre as ideias dos alunos a posteriori, aplicando o mesmo instrumento do momento inicial.

5. Aplicação de um instrumento de metacognição aos alunos para monitorizar o processo de ensino e aprendizagem. ${ }^{12}$ 
É possível verificarmos que não se trata de um passo a passo prescritivo, mas de fases que são compostas por diferentes tarefas, mais ou menos complexas. O objetivo deste modelo de aula é a progressão do conhecimento histórico abarcando conceitos dos conteúdos substantivos específicos e, muito mais, os conteúdos de segunda ordem, perceptíveis a partir da narrativa histórica produzida pelos estudantes que é o foco de todo o processo de desenvolvimento da aula, desde seu planejamento até a reflexão posterior às aulas. A "recolha de dados sobre as ideias dos alunos" no início e no final do processo demonstra a preocupação fundamental deste modelo e evidencia o objetivo de superar os paradigmas que tinham no professor o detentor do conhecimento e no estudante uma tábula rasa receptora de informações.

Todo o processo de ensino e de aprendizagem é reconfigurado. A função do professor é orientar o processo de pesquisa, análise de fontes e desenvolvimento da narrativa histórica, etapas protagonizadas pelo estudante. Este pode, portanto, demonstrar traços progressivos em sua narrativa na medida em que o professor apresenta e trabalha com diferentes conteúdos substantivos e de segunda ordem. O trabalho docente passa a ser mais qualificado na medida em que se torna necessário o domínio de metodologias e pressupostos teóricos para que o exercício do ensino de história supere a narração linear, e passe a conduzir uma construção de conhecimentos históricos no cotidiano da sala de aula.

Pensando no objetivo desta pesquisa, temos agora a oportunidade de esclarecer que não se trata da elaboração de planos de aula, mas de uma reflexão sobre formas possíveis de se trabalhar com o conteúdo objetivo selecionado, apontando para práticas que levariam os estudantes a pesquisar e a desenvolver narrativas históricas cada vez mais refinadas com as ferramentas historiográficas. Dessa maneira, o conhecimento histórico pode ser "internalizado de forma que intervenha nas ideias/ações dos sujeitos de modo que enriqueçam o senso comum transformando-os em senso crítico". ${ }^{33}$ Portanto, faz-se necessário um breve aprofundamento sobre as diferentes fases apontadas por Barca para o desenvolvimento da Aula-Oficina.

\section{COLETA, ANÁlISE E CATEGORIZAÇÃo DAS IDEIAS PRÉVIAS}

A prática de recolher as ideias prévias dos estudantes já é recorrente e bastante 
difundida de maneira informal. O que Barca sugere é que seja feita de maneira sistemática. Essa fase do trabalho é identificada como a primeira e a última da matriz disciplinar de Rüsen. Problemas e angústias do presente são o ponto de partida para os interesses tanto do historiador profissional quanto para a curiosidade do estudante da educação básica quando iniciam as perguntas sobre sua existência e buscam as respostas históricas. Este é um traço da consciência histórica da qual não há possibilidade de se desvencilhar.

Para conseguir coletar as ideias prévias e, consequentemente, os traços das consciências históricas dos estudantes a partir de suas narrativas, o professor pode se utilizar de formas escritas simples, produzidas em sala, como questionários prévios, redações, descrições, de formulários eletrônicos com questões diagnósticas diversas, ou mesmo do brainstorm, método pelo qual as ideias prévias são lançadas pelos estudantes e o professor as anota no quadro. Se forem devidamente sistematizadas pelo professor, estas ideias coletadas subsidiarão a análise a respeito de quais conceitos históricos e suas interpretações predominam na turma em questão. Com a análise minuciosa desses elementos, o professor tem acesso a indícios da cultura e da consciência histórica dos estudantes.

Segundo Cerri, a cultura histórica determina as formas pelas quais as narrativas são usadas para orientar ou justificar as ações individuais e coletivas dos sujeitos no presente. $\mathrm{O}$ conceito de cultura histórica "delineia um conjunto de fenômenos histórico-culturais representativos do modo como uma sociedade ou determinados grupos lidam com a temporalidade [...] ou promovem usos do passado". ${ }^{14}$ É o conjunto de saberes históricos que estão assimilados pelas pessoas e, a partir destes, toda a vida, passada e presente, é significada e a perspectiva de futuro é criada.

As respostas e ideias apresentadas pelos estudantes são indícios de como os grupos dos quais eles fazem parte compreendem e significam sua vivência histórica, sejam esses grupos familiares, comunitários, regionais ou mesmo nacionais. As formas pelas quais os estudantes se identificam, como se relacionam com os grupos identificados como "o outro", se compreendem determinados processos históricos como positivos ou negativos, entre diversos outros aspectos, são importantes para delinearmos estratégias de trabalho em sala e, ainda mais essencial, para percebermos que o conhecimento histórico não é monopólio do ensino escolar e acadêmico. Ele é resultado de todos "os conhecimentos e opiniões que circulam em suas famílias, na igreja ou outras instituições que frequentam e nos meios de comunicação de massa aos quais tem acesso". ${ }^{15}$ 
Para significar o mundo e sua própria existência o ser humano se vale de sua historicidade, que é a própria condição da existência humana, é algo que nos constitui enquanto espécie. Em outras palavras, "pensar historicamente é um fenômeno, antes de qualquer coisa, cotidiano e inerente à condição humana". ${ }^{16}$ Ao atribuirmos significados, escolhermos determinadas roupas ou cortes de cabelo, ingerirmos determinados alimentos cotidianamente, utilizamos uma língua para nos comunicar ou mesmo praticar determinada religião, estamos imersos em camadas históricas que condicionam nossas práticas e nossas estruturas mentais. "A consciência histórica nos dá elementos para nos orientar quando precisamos enfrentar um problema no presente, nos impelindo a uma relação interpretativa do passado para buscar subsídios para o agir, e assim, interferir no futuro". ${ }^{17}$ A consciência histórica, portanto, é um atributo universal o que torna o pensamento histórico acadêmico, sua prática especializada.

O que está por trás desta fase do trabalho em sala de aula é a tentativa de perceber as formas de consciência histórica presentes na turma. Esta preocupação é importante, pois parte desta percepção o planejamento das formas de se ensinar história que sejam alicerçadas nos significados históricos pré-existentes dos alunos, algo que quando não observado, contribui para que o ensino de história seja uma sequência de datas e fatos “insignificantes”, os quais serão regurgitados e esquecidos após o teste escrito. Dessa forma, uma melhor conceituação da consciência histórica pode nos ajudar a desenvolver este trabalho.

Em seu trabalho, Ensino de história e consciência histórica, o professor Luis Fernando Cerri desenvolve uma longa análise, embasada em Agner Heller e Jörn Rüsen, na qual argumenta que existem diferentes consciências históricas as quais explicam nossa existência, justificam nossas instituições e costumes e até mesmo determinam nossos pensamentos. Elas estão presentes em todos os seres humanos, em todos os lugares e tempos, sendo uma condição da existência humana e a base para a formação identitária, aquilo que define o "eu", o "nós" e o "eles". É a consciência histórica que integra as dimensões do passado, do presente e do futuro. Ela forma, em última análise, a coesão social e fundamenta as instituições, desde as sociedades antigas e tradicionais até os modernos Estados-nação. Cerri argumenta que para explicar consciência histórica é preciso usar "uma definição muito ampla de história, como tempo significado [...]. Consciência histórica não é memória, mas a envolve [...], não é definida aqui como conquista particular, mas como aquisição cultural 
elementar". 18

Por se tratar de um atributo inerente ao ser humano, com aspectos diversos, com diferentes formas não hierarquizadas e com nuances de diferentes manifestações da consciência histórica no mesmo indivíduo, definir a consciência histórica de um estudante ou de uma turma é tarefa praticamente utópica. Entretanto, os sinais da cultura e da consciência histórica, expressos pelos estudantes enquanto ideias prévias são passíveis de análise e podem viabilizar o planejamento e a implementação do conteúdo selecionado de forma historicamente significativa. Esses sinais demonstram se determinados conceitos de segunda ordem precisam ser trabalhados de forma prioritária, se há aspectos ligados ao conteúdo substantivo específico que reforçam preconceitos ou autoritarismos históricos e precisam ser minados através de pesquisa e mesmo se alguns desses conceitos já são suficientemente desenvolvidos pela turma. "Não compete ao trabalho da história na escola formar a consciência histórica dos alunos - eles já chegam com suas consciências formadas em traços fundamentais -, mas possibilitar o debate, a negociação e a abertura para a ampliação e complexificação das formas de atribuir sentido ao tempo que os alunos trazem com eles". ${ }^{19}$

Esta fase do processo de ensino se torna um esforço para compreender a história que o aluno usa: vivida, sensível, enviesada, a qual confere sentido a sua experiência de vida, familiar e social. A compreensão de traços da consciência histórica dos estudantes possibilita uma aproximação da história vivida com a que nos propomos a ensinar, mais complexa, ampla e com diferentes atribuições de sentido ao tempo.

Desenvolvemos, em nosso produto educacional que resultou da pesquisa no ProfHistória, algumas sugestões práticas para a aplicação desta etapa da Aula-Oficina. Nos utilizando do conteúdo substantivo por nós selecionado, a abertura política e momento constituinte, apontamos três possibilidades simples para a coleta das ideias prévias. Tendo como base a possibilidade de trabalho em formatos presenciais, remotos ou híbridos, apontamos produções textuais, a partir de simulação de uma conversa pelo Whatsapp sobre a temática proposta ou a produção de um texto, ambos com apontamentos de conceitos-chave a serem utilizados. Também sugerimos o preenchimento de um formulário eletrônico no qual os estudantes poderão apresentar seus conceitos prévios de diferentes maneiras. Após uma breve introdução ao tema, inserimos vinte afirmativas ligadas aos direitos fundamentais e sociais, à cidadania, à constituição, à constituinte e à participação popular na política. Dentre estas afirmações algumas confirmam esses direitos, outras os negam. As considerações dos 
estudantes, para cada afirmação, são escalonadas em três níveis: concordância, discordância ou indiferença. Solicitamos também que eles apontem, digitando livremente sua opinião, justificativas para duas concordâncias e para duas discordâncias, ambas de sua livre escolha.

Uma última proposta de coleta das ideias prévias é a prática, comum no meio corporativo, do brainstorming ou tempestade de ideias. O professor lança o tema central da próxima unidade temática e os estudantes poderão mencionar conceitos, frases e ideias que eles acreditam estarem ligados ao tema. É essencial que não haja julgamentos, atribuindo valor de "certo" ou "errado" e que os estudantes sejam incentivados a mencionar a maior quantidade de ideias possível para posterior análise do resultado. Pode ser feita a partir da anotação dos apontamentos e dos conceitos no quadro ou a partir da utilização de ferramentas eletrônicas como o site Mentimeter que disponibiliza a WordCloud (Nuvem de Palavras).

Todas as nossas sugestões tratam de práticas simples que, por diferentes meios, possibilitam ao professor evidenciar a voz do estudante para que ele exprima traços de sua cultura e consciência histórica. Tem início, a partir de então, o trabalho de análise dos resultados. O professor também percebe quais os conteúdos de segunda ordem devem ser trabalhados com mais destaque, como historicidade, permanência, ruptura, etc. Esta etapa nos fornece as informações necessárias para o começo do trabalho de planejamento e implementação das aulas.

\section{PLANEJAMENTO E IMPLEMENTAÇÃO DA UNIDADE TEMÁTICA}

O relato de experiência, quase em tom de anedota, feito por Pereira e Seffner, no qual a narração nos envolve em uma aula de estagiário da graduação, com a presença do professor-supervisor de campo (este, o autor do artigo), com direito a descrição do clima e do ambiente, nos é sugestivo, pois os acontecimentos imprevistos daquela tarde culminaram em uma aula significativa e produtiva. Por mais que o professor-estagiário se esforçasse, apresentasse o conteúdo, pinturas e outras fontes históricas, o diálogo com a turma não fluía e a aula caminhava para um desastre pedagógico. Como o tema era a escravidão no Brasil e a maioria da turma, ainda segundo o relato, era composta por estudantes negros e pobres, o som da sirene policial fez com que uma das estudantes ligasse conceitualmente o conteúdo trabalhado às situações cotidianas de racismo e racismo estrutural pela qual ela passava, o que resultou em uma enxurrada de observações semelhantes pelos outros estudantes. Esta situação 
imprevista foi aproveitada pelo professor que conduziu a discussão a partir daí. Nas palavras do autor, "a tarde foi salva pela sirene da polícia" 20

Esta narrativa é interessante na medida em que percebemos uma eventualidade que veio a salvar o andamento de uma aula que, provavelmente, havia sido cuidadosamente planejada, inclusive em seus aspectos teórico-metodológicos, mas não estava sendo significada pelos estudantes. Entretanto, acreditamos que felizes coincidências não podem ser esperadas na prática do ensino de história pela óbvia razão de serem imprevistas. A reflexão intencional e cuidadosa, a partir dos resultados das ideias prévias dos estudantes, deve conduzir a estrutura das aulas nunca perdendo de vista os objetivos do ensino de história. É a partir destes resultados que o professor tem condições de perceber nuances da consciência e da cultura histórica dos estudantes bem como do grau de literacia histórica. Dessa forma, o desenvolvimento das aulas se potencializa para um trabalho significativo que possibilite uma evidente progressão do conhecimento.

Ensinar história, portanto, muito mais do que ensinar a ser patriota, ser religioso, ser moralmente correto a partir do ensino de fatos, personagens e datas modelo, é ensinar a pensar historicamente. É através do ensino de ferramentas que os estudantes poderão usar evidências históricas para significar sua vida. Aprender sobre o processo constituinte no Brasil do final da década de 1980, por exemplo, deve ser importante na medida em que os estudantes compreendam mais do que nomes de deputados e senadores constituintes representantes de sua cidade ou região, mais do que memorizar datas e resultados de eleições e de votações no congresso ou trechos da própria Constituição. Eles devem compreender, após o trabalho com esta unidade temática, que a população da época fez parte de um processo constitucional e se organizou para defender interesses de classe e de categorias, as quais, nos trabalhos constitucionais anteriores, não tinham sido ouvidos; aprender sobre este tema deve ser importante para que eles compreendam também que processos de transição e de crise política são marcados por permanências, reminiscências, rupturas. Em outras palavras, o ensino deste conteúdo substantivo deve ser pautado pela preocupação com os conceitos de segunda ordem que envolvem o processo em questão. Esse processo possibilitaria o desenvolvimento da literacia histórica.

A este conceito pode ser feito um paralelo com a ideia de letramento linguístico no qual estão envolvidas as competências de leitura e compreensão linguísticas. Peter Lee aponta para alguns princípios que podem conceituar a literacia histórica: 
Uma primeira exigência da literacia histórica é que os alunos entendam algo do que seja história, como um "compromisso de indagação" com suas próprias marcas de identificação, algumas ideias características organizadas e um vocabulário de expressões ao qual tenha sido dado significado especializado: "passado", "acontecimento", "situação", "evento", "causa", "mudança" e assim por diante. Isso sugere que os alunos devem entender, por exemplo:

- como o conhecimento histórico é possível, o que requer um conceito de evidência;

- que as explicações históricas podem ser contingentes ou condicionais e que a explicação de ações requer a reconstrução das crenças do agente sobre a situação, valores e intenções relevantes;

- que as considerações históricas não são cópias do passado, mas todavia podem ser avaliadas como respostas para questões em termos (ao menos) do âmbito do documento que elas explicam, seus poderes explicativos e sua congruência com outros conhecimentos. $^{21}$

Podemos afirmar, portanto, que o estudante letrado historicamente é capaz de compreender que a narrativa histórica é uma construção, com características e conceitos próprios, baseada em evidências, as quais são traços de intenções dos narradores e que as explicações do passado partem de questões elaboradas por pessoas do presente a partir de problemas do presente. Segundo Peter Lee, estes são os conceitos de segunda ordem, os quais evidenciam a importância do trabalho cotidiano com fontes históricas, cabendo aos textos narrativos o papel introdutório ou explicativo (no caso de conceitos que careçam de aprofundamento). A pesquisa, interpretação, análise das fontes, levantamento do contexto, das contradições, enfim, o trabalho de análise histórica do tema, período e processo estudado devem ser protagonizados pelos estudantes, sempre guardadas as possibilidades ligadas à idade e à série da turma. O ensino de história com base na análise de fontes históricas, portanto, é possível desde as séries iniciais. Cabe ao professor a adequação do trabalho desde a seleção do tema e das fontes até as abordagens. O trabalho com fontes históricas em sala de aula, dessa forma, nos remete a duas das fases da matriz disciplinar de Rüsen, as ideias e o método. A fase classificada como Ideias se caracteriza por se tratar da fundamentação e dos referenciais teóricos, segundo os quais se atribui sentido às interpretações do passado e à orientação da vida. A fase do Método, por sua vez, pode ser definida como o caminho pragmático da pesquisa ou como os procedimentos regrados que conferem plausibilidade ao conhecimento histórico. São os procedimentos práticos que definem as formas pelas quais distintas fontes históricas precisam ser trabalhadas, quais as perguntas devem ser feitas para elas e quais os limites de interpretação de cada uma.

Esta é a base do modelo de aula-oficina. O professor exerce a função de orientador e organizador de atividades problematizadoras porque é o estudante quem desenvolve a função de agente do processo de aprendizagem ao protagonizar a pesquisa 
histórica. A partir das experiências dos estudantes o professor pode indicar este ou aquele caminho que possibilitará a apreensão de mais e mais ferramentas históricas, mas a narrativa, produto final de cada unidade de pesquisa, é do estudante.

Enquanto apontamentos práticos para o trabalho com fontes em sala de aula, entendemos como necessárias algumas considerações acerca de questões metodológicas para a análise de determinadas categorias de fontes por nós selecionadas. Para tanto, pensando no trabalho cotidiano de professores, como nós, apontaremos referências extraídas de bibliografia especializada em ensino de história e presente nas Bibliotecas do Professor das escolas da rede estadual do Paraná. São obras adquiridas por meio de recursos do Fundo Nacional de Desenvolvimento da Educação (FNDE), vinculado ao Ministério da Educação, em diferentes programas entre 2010 e 2013. Assim, algumas das bibliografias de onde levantamos os apontamentos metodológicos a seguir estão disponíveis ao menos para os professores da rede estadual de nosso Estado.

Não é o objetivo do ensino de história tornar todos os estudantes da educação básica historiadores profissionais, mas apresenta-los às ferramentas do Metier de L'Historien ${ }^{22}$ (ofício do historiador), de forma a significar sua historicidade enquanto tal, para que possam desenvolver e sofisticar sua cultura e consciência histórica refletindo sobre sua própria existência. Dessa forma, ao apresentar diferentes documentos, abordagens e temas aos estudantes e ensinarlhes os diferentes métodos e critérios de análise destes documentos, o professor precisa "passear" por diferentes pressupostos teóricos da História enquanto ciência. Este é o ponto que torna o trabalho qualificado no sentido de ser necessária a compreensão de conceitos básicos destas diferentes linhas teóricas que serão desenvolvidas em sala, mesmo que em um nível menos profundo quando comparado a uma produção historiográfica acadêmica.

Seja qual for a linha teórica adotada pelo professor nesta ou naquela aula, alguns princípios metodológicos são essenciais para a análise e interpretação de qualquer fonte histórica que possibilite a construção do conhecimento histórico. $\mathrm{O}$ estudante, para compreender que este conhecimento é provisório e constantemente construído, deve ter condições de aprender e exercitar alguns dos procedimentos próprios da história: "problematização das questões propostas, delimitação do objeto, exame do estado da questão, busca de informações, levantamento e tratamento adequado das fontes, percepção dos sujeitos históricos envolvidos [...] proposta de explicação para fenômenos estudados, elaboração de exposição, redação de 
textos". 23

Todas estas são questões básicas no tratamento e análise das fontes que podem ser desenvolvidos de forma gradual pelo professor que, com intenções claras, pode definir sequências de trabalho que possibilitem a progressão destes pontos fundamentais, o que em tese, se caracteriza pelo desenvolvimento da literacia histórica dos estudantes.

De forma prática, podemos apontar procedimentos possíveis e necessários para a análise e interpretação de diferentes fontes históricas em sala de aula. Segundo Schmidt e Cainelli, o trabalho passa pela identificação, explicação e comentário do documento. A identificação "não é uma simples leitura do documento. Significa um trabalho que passa por várias fases e pode ser considerado um primeiro olhar crítico sobre o documento”. A explicação, por sua vez, é diferente. "Explicar o documento significa fazer o aluno confrontar seus conhecimentos ou os dados que obteve em uma pesquisa com os elementos constitutivos do documento". 24

Na primeira fase, de identificação, é importante que os estudantes aprendam a categorizar as fontes de acordo com sua tipologia: fontes materiais, fontes escritas, fontes visuais ou fontes orais. Além disso, a natureza da fonte determina diferentes abordagens de análise: documentos oficiais, documentos descritivos, documentos opinativos, documentos religiosos, documentos não expressivos, porém significativos. Já para a segunda fase, a explicação do documento, o estudante deve contextualiza-lo e observar, de forma crítica, como o conteúdo se relaciona com fatos, dados e interpretações historiográficas apresentadas pelo professor ou que ele obteve a partir de pesquisas prévias.

Todos estes procedimentos são importantes e garantem, em sala de aula, o rigor metodológico do trabalho do historiador para que não caiamos em armadilhas interpretativas, como, por exemplo, os anacronismos. São encaminhamentos importantes a serem seguidos em todas as aulas nas quais os documentos serão apresentados aos estudantes. Por isso a importância de exercícios que sedimentem este método, reiteradas vezes, o que tornará a postura crítica dos estudantes perante qualquer situação, mesmo cotidiana, uma prática naturalizada.

\section{IDEIAS POSTERIORES - UMA POSSIBILIDADE DE AVALIAÇÃO}

O momento da avaliação foi arraigado de tal forma na cultura escolar pelos 
modelos de educação tradicional que no cotidiano da escola temos dificuldades essenciais ao tratar do tema e discutir formas de se analisar o conhecimento construído pelos estudantes de forma qualitativa. O próprio sistema de avaliação, classificatório e constituinte de escalas percentuais, torna o teste escrito um fim para a aprendizagem o que, segundo os modelos de educação democráticos e progressistas, em especial o modelo de aula-oficina, não faz o menor sentido.

Se pensarmos que, no caso específico do ensino de história, a função de desenvolver a literacia histórica tem como objetivo a atribuição de sentidos historicizados pelo estudante à sua existência de maneira progressiva, testes escritos do tipo erro-acerto não são suficientes. O cerne do ensino de história não pode ser um relatório quantitativo dos conceitos aprendidos e reproduzidos por escrito, mas a progressão e a significação de conceitos que paulatinamente se tornam mais amplos e complexos, suficientes para serem aplicados de forma reflexiva na vida cotidiana dos estudantes. A quarta fase da matriz disciplinar rüseniana trata deste conceito, pois de acordo com os princípios desta fase, a Apresentação, o resultado de qualquer pesquisa histórica, profissional ou, no nosso caso, escolar, deve ser a comunicação da pesquisa de forma pública, portanto com linguagem inteligível. Nesta fase a pesquisa científica ganha nuances de arte ao se valer de discurso narrativo, passível de compreensão para que a reflexão entre seus resultados e a vida prática seja possível.

Compreendemos que esse é um grande desafio para a prática do ensino de história: a conclusão de uma unidade temática, com mecanismos de verificação da aprendizagem que não resultem em procedimentos sistemáticos de levantamento de dados quantitativos, o que compreendemos não ser positivo. Mas que resulte em análises qualitativas da progressão do conhecimento histórico com base na apreensão e utilização de ferramentas históricas desenvolvidas ao longo do processo.

Ao final do processo de ensino de qualquer conteúdo substantivo espera-se que os estudantes sejam capazes de elaborar narrativas sobre os conhecimentos adquiridos, tanto ligados ao conteúdo específico quanto às novas ferramentas históricas que eles desenvolveram neste processo. Com base nestas novas narrativas construídas pelos estudantes é que o professor deve trabalhar de forma a perceber as ideias posteriores no sentido de comparar com aquelas apresentadas no início do processo. Esse trabalho, que pode variar de acordo com a seleção de diferentes instrumentos de produção narrativa, possibilita a 
compreensão, por parte do professor, de quais conteúdos, substantivos ou de segunda ordem, foram significativamente compreendidos e levaram à progressão do conhecimento histórico dos estudantes.

Progressão do conhecimento histórico, compreensão de ferramentas históricas, significação do tempo, historicidade das instituições, costumes e práticas, são aspectos das diferentes formas de compreensão, conceituada como consciência histórica, a qual toma forma pelo modo de operação mental que constrói as diferentes formas narrativas. Ao serem diferentemente configurados, os modos de operação mental são classificados como tipos ideais, ou seja, abstrações impossíveis de serem aplicadas de forma pura no processo dinâmico real e que muitas vezes se misturam entre si e se confundem. Os tipos ideais são, portanto, instrumentos de interpretação das ações sociais para descrevê-las e compreendê-las. Os tipos ideais "permitem reconhecer apenas aspectos das pessoas, instituições ou acontecimentos". ${ }^{25}$

Os tipos ideais de geração de sentido histórico, apresentados por Cerri, foram classificados em quatro modos. O primeiro modo, de sentido tradicional, é marcado por priorizar a valorização das origens das atuais formas de organização de nossa vida. Expressões como "sempre foi assim" ou "precisamos preservar nossas tradições" são marcas deste modo. A manutenção da ordem é um dos principais objetivos e as comemorações ritualísticas são exemplos de como as origens são valorizadas a ponto de não serem refletidas ou questionadas. O segundo modo, de sentido exemplar, é típico do arquétipo presente na expressão historia vitae magistra (história mestra da vida, que caracterizou a historiografia ocidental desde a antiguidade até o século XVIII), segundo o qual o passado exerce a função de reforçar as regras do presente por meio de exemplos a serem seguidos ou evitados. $\mathrm{O}$ terceiro modo, de sentido crítico, prioriza as rupturas e contradições no sentido de buscar novas práticas sociais. O tempo é julgado para que padrões dominantes sejam subvertidos e alterados, revertendo a cultura histórica dominante. $\mathrm{O}$ quarto e último modo, genético de sentido histórico, explica a realidade através da passagem do tempo em si. Passado, presente e futuro são compreendidos de forma dinâmica por meio de diferentes perspectivas que garantem uma integração abrangente de diversos aspectos da realidade e do tempo. A orientação da vida se organiza em função da perspectiva da mudança em si, a identidade histórica, portanto, se torna o próprio processo de mudança. ${ }^{26}$

Essencial, entretanto, compreender que esses quatro tipos ideais não são 
aplicáveis de maneira pura para classificar indivíduos ou grupos e tampouco são hierarquizáveis. Podemos ser tentados a afirmar que o modo genético de sentido histórico é melhor, mais completo portanto, seria o ápice de uma jornada de evolução do pensamento histórico que precisa galgar, degrau a degrau, pelos outros modos de atribuição de sentido. Essa premissa é falsa pois as atribuições de sentido aparecem em diferentes formas a partir dos mesmos indivíduos, dependendo do contexto, das origens ou dos temas abordados. Alguém com atribuições de sentido genético em determinada área pode conferir sentido de maneira tradicional em outra. Compreender como são expressos os nuances de sentido, mesmo fragmentados, parciais e enviesados, nos possibilita uma análise qualitativa das narrativas produzidas pelos estudantes, percebendo um ou outro modo predominante em cada uma das situações trabalhadas em sala.

De forma objetiva, podemos afirmar que o formato pelo qual a produção narrativa seria desenvolvida pelos estudantes não possui grandes limitações. O professor, junto dos estudantes, pode se valer de pesquisa e criatividade para criar diferentes estratégias narrativas. Se a opção for pela produção escrita, diferentes gêneros textuais possibilitam uma infinidade de trabalhos, como cartas, descrições, roteiros, reescrita de textos literários, etc. Há a possibilidade de se optar por encenações teatrais ou, se valendo do atual período de expansão do uso de mídias online, animações, gravações, edições de vídeos também são pertinentes. Há a possibilidade de criar e alimentar sites e blogs. É possível a utilização, até mesmo, de questões objetivas que extrapolem a noção de certo-errado, priorizando a noção de progressão do conhecimento histórico. Percebemos, portanto, que as possibilidades são numerosas e permitem aos estudantes a produção de narrativas que demonstrariam sua compreensão do processo estudado e, principalmente, as ferramentas históricas adquiridas por eles.

A depender do instrumento utilizado pelo professor, as expressões da consciência e da cultura histórica dos estudantes, antes e depois do trabalho desenvolvido em cada unidade temática, poderão ser expressas e analisadas por meio da competência narrativa que o estudante poderá desenvolver. Esta competência é subdividida em três categorias: (1) competência da experiência que se refere a identificar o passado como tal e diferenciá-lo do presente, (2) competência de interpretação segundo a qual a capacidade de atribuir significados e sentidos a eventos do passado é desenvolvida e (3) a competência de orientação, que se caracteriza pelo letramento histórico, pois com ela é 
possível, além de conhecer e interpretar o passado, utilizar este conhecimento para a própria vida, organizando os cursos da ação pessoal e do engajamento coletivo com base nestas análises históricas. ${ }^{27}$

O fechamento do ciclo da matriz disciplinar marca o início de um novo ciclo, pois a última fase, as Funções do aprendizado histórico, se confunde com a primeira, os Interesses, na medida em que o retorno da reflexão histórica para a vida prática conduz ao surgimento de novas questões, as quais iniciam novo processo de investigação histórica. "O conhecimento produzido, se bem apresentado ao destinatário, serve para intervir em seu modo de viver, pensar e agir, portanto, assume 'utilidade existencial', assumindo Funções na vida prática". ${ }^{28}$

Com base nesta breve reflexão sobre os conceitos teórico-metodológicos para a prática do ensino de história, pudemos analisar os principais objetivos e algumas possibilidades de atuação em sala de aula. Diversos autores que pesquisam o tema e trabalham a matriz disciplinar de Rüsen entendem que ponto de partida e o ponto de chegada são os mesmos: os interesses que os estudantes trazem do mundo real, oriundos dos conhecimentos históricos adquiridos na escola ou fora dela, e a utilidade destes conhecimentos para a sua vida prática. As demais fases, ideias, métodos e apresentação, só tem sentido se o processo como um todo dialogar com a primeira e a última fase. Os procedimentos e reflexões a respeito da AulaOficina, por sua vez, demonstram que este modelo de aula foi pensado por Isabel Barca no sentido de tornar a aula de história um lugar privilegiado para a pesquisa e a produção do conhecimento histórico, levando em conta a consciência histórica que os estudantes já possuem para que, por meio do trabalho escolar, elementos da cultura histórica sejam enriquecidos e as significações de sua vida cotidiana possam superar o senso comum.

Dessa forma, iniciamos agora o desafio de propor reflexões práticas acerca do ensino e pesquisa em sala de aula sobre o período de abertura política e redemocratização no Brasil no fim da década de 1980, embasados nos princípios teórico-metodológicos tratados neste capítulo. Portanto, nossa proposta para as próximas página é refletir sobre práticas de ensino que garantam a construção do conhecimento histórico em sala de aula sobre esse tema e período por estudantes e professores. Iremos apresentar os documentos selecionados como possíveis de serem trabalhados em sala de aula, breves questões metodológicas para o trabalho com diferentes fontes históricas, algumas novas ferramentas online e ferramentas tradicionais, que contribuirão de forma significativa com o trabalho de ensino de história na educação básica. 
Dessa forma, uma possibilidade interessante de trabalho é a aplicação da mesma proposta do início dos trabalhos, ou seja, da coleta das ideias prévias. As mudanças conceituais serão diretamente expostas e possíveis de classificação pelo professor. Outra proposta seria a produção textual de narrativas com base em roteiro ou situação problema, a partir da qual o estudante pode desenvolver explicações ou narrações que abordem o tema e o período proposto.

Essas produções narrativas podem ter inúmeros formatos. Tradicionalmente as produções escritas são sobrevalorizadas e, devido à sua utilização ao longo das décadas, se tornou naturalizada e menos trabalhosa para a correção. A ideia de produzir narrativas que serão válidas enquanto ferramenta para a vida cotidiana dos estudantes parte do princípio que diferentes plataformas devem ser desenvolvidas ao longo de sua da vida escolar, daí a importância de desenvolver sim narrativas escritas, afinal essa habilidade é essencial para a vida em sociedade, mas também é importante desenvolver ferramentas orais, visual ou até virtuais.

Situações de apresentação do tema para a turma ou mesmo para outras turmas potencialmente desenvolvem a retórica e a oratória, cabendo ao professor, no processo avaliativo, analisar a estrutura do discurso, a postura e as expressões além dos conceitos históricos próprios da apresentação. Representações artísticas também são válidas no sentido de perceber como o estudante representa este ou aquele conceito trabalhado em sala e como ele representa algum dos conteúdos específicos pesquisados. Debates são ferramentas interessantes pois os estudantes possuem tendências competitivas e, ainda como tendência, buscariam mais e mais elementos narrativos para o debate afim de "ganhar a discussão" o que, durante o processo, garantiria uma aprendizagem ainda mais profunda. $\mathrm{O}$ debate, inclusive, figura como importante ferramenta para a democracia em si, visto que a pluralidade de ideias depende de debates para que consensos sejam construídos. Outro exemplo a ser apontado, são as produções midiáticas. Generalizadas devido à pandemia e ao ensino remoto, as ferramentas multimídia se popularizaram e se tornaram presentes em nosso cotidiano, portanto, seu uso é não só necessário, mas produtivo e interessante. A depender do nível de cultura histórica dos estudantes, eles podem produzir vídeos, entrevistas, tutoriais, até desenvolver projetos maiores como rádio-escola, podcasts, ou canais do youtube.

Uma última sugestão tem base em uma experiência que desenvolvemos, de maneira quase informal à época, mas que produziu resultados interessantes. Dentro de um 
projeto que envolvia toda a escola, as turmas eram organizadas para apresentarem encenações de recortes do tema selecionado em cada edição anual do projeto. Em uma das edições, o tema era a história política do Brasil e um dos grupos encenou o processo constituinte. A partir desta experiência e com base nos elementos teórico-metodológicos de nossa pesquisa, acreditamos que um processo constituinte simulado seria propício para uma realidade em que o professor entender que os estudantes desenvolveram ou podem ter desenvolvido ferramentas suficientes para colocar em prática os conhecimentos sobre cidadania, constituição e participação aprendidos durante o processo desta temática.

É possível inclusive, que se valendo de algum projeto maior, a turma em questão, junto do professor, desenvolva um projeto de aprendizagem que envolva toda a escola, por exemplo, para elaborar o regulamento de uma gincana. Sabemos, por experiência, que recursos financeiros oficiais sempre são insuficientes para sanar todas as necessidades de uma escola. Por isso, é prática comum a Associação de Pais, Mestres e Funcionários - APMF, entidade privada e sem fins lucrativos que gerencia os recursos financeiros da escola, mobilizar a comunidade em promoções ou eventos em prol da arrecadação de recursos para complementar os repasses oficiais. Não iremos entrar na questão sobre a validade ou não desta prática, mas apenas constatamos essa situação cotidianamente e sabemos que está dentro dos limites da legalidade desde que os recursos adquiridos com a comunidade sejam executados de maneira transparente e para fins educacionais.

Um dos eventos mais tradicionais e disseminados que é desenvolvido pela APMF são as festas folclóricas (junina, sertaneja, da primavera, etc.). Em geral, há gincanas de arrecadação de produtos e prendas para serem sorteados/vendidos no dia do evento. É neste ponto que entra nossa proposta de atividade avaliativa para nossos estudantes. $\mathrm{O}$ professor e a turma podem organizar a eleição de uma Assembleia Constituinte do regulamento da gincana. Assim, todos os conceitos ligados à participação, cidadania, argumentação, narrativa, serão desenvolvidos e o regulamento, que terá caráter legal para a comunidade escolar, será produzido a partir de negociações e debates, vivência próxima à uma assembleia real.

Enfim, todos os apontamentos que apresentamos tem o objetivo de refletir sobre a prática avaliativa e refletir sobre formas de se analisar a pertinência e efetividade da produção do conhecimento pelos nossos estudantes. Reafirmamos que não são apontamentos prescritivos, mas sugestões reflexivas de trabalho contínuo e processual para a produção do conhecimento histórico dos estudantes. Na próxima seção iremos apresentar as fontes 
específicas que selecionamos para nossa proposta e desenvolver, metodologicamente, possibilidades de trabalho com cada uma delas em sala de aula.

\section{CONSIDERAÇÕES FINAIS}

Nossa proposta de produto tem como base a construção de sequências didáticas caracterizadas pela liberdade intelectual de professores e de estudantes. Ao propor aulas-oficina, não faz sentido entregarmos roteiros de aula para serem seguidos como se fossem receitas culinárias. Não temos a pretensão de ensinar nossos colegas de trabalho, professoras e professores de história da educação básica a dar aulas. Sabemos que todos aqueles que vivenciam o cotidiano escolar ensinando história diariamente, nas salas de aula tradicionais ou através de novas modalidades de ensino que foram amplificadas pela ocorrência da pandemia, são capacitados, conhecem ferramentas, conteúdos, práticas e dominam os preceitos teórico-metodológicos do ensino de história. Como professores da educação básica, conhecemos a realidade e os desafios de nossa profissão e apresentamos os resultados da presente pesquisa como uma pequena contribuição com base nas considerações sobre o tema específico e a metodologia específica que selecionamos como recorte de nosso trabalho.

Muito mais do que dizer, por exemplo, quantos minutos da aula o professor deve utilizar para introduzir os temas ou para ler determinado texto, acreditamos, com base em nossa pesquisa, que reflexões sobre a pesquisa histórica, sobre os métodos de análise e interpretação de fontes históricas e a apresentação de diferentes possibilidades de produção narrativa é mais significativa para pensarmos o ensino de história na Educação Básica.

Assim, nosso objetivo ao apresentar este artigo é de alguma maneira contribuir para as reflexões teóricas e metodológicas do ensino de história na educação básica garantindo que o rigor metodológico da pesquisa historiográfica seja, a partir dos princípios da didática da história, aplicado para o desenvolvimento de uma cultura histórica que possibilite aos estudantes compreender o mundo de forma historicamente fundamentada, percebendo as instituições, situações e relações cotidianas de forma historicizada.

\footnotetext{
${ }^{1}$ Disponível em <https://www.projetochave.com.br/sequencias-didaticas-ideias-prévias>. Acesso em 08 jul. 2021.

${ }^{2}$ RAMOS, Márcia Elisa Teté. Considerações sobre a construção da história escrita, ensinada e divulgada através da matriz disciplinar de Jörn Rüsen. In. Diálogos. Maringá. v. 22, n. 3. 2018, p. 38.

${ }^{3}$ BARCA, Isabel. Ideias chave para a educação histórica: uma busca de (inter)identidades. História Revista, Goiânia, v. 17, n. 1, p. 37- 51, 2012, p. 37.
} 
${ }_{5}^{4}$ RAMOS, Márcia Elisa Teté. Op cit, p. 36.

${ }^{5}$ ALBUQUERQUE JÚNIOR, Durval Muniz de. Fazer defeitos nas memórias: para que servem o ensino e a escrita da história? In: GONÇALVES, Márcia de Almeida; ROCHA, Helenice; REZNIK, Luís, MONTEIRO, Ana Maria. (Org.). Qual o valor da história hoje? Rio de Janeiro: Editora FGV, 2012, p. 32.

${ }^{6}$ CAINELLI, Marlene Rosa; TOMAZINI, Elizabete Cristina de Souza. A Aula-Oficina como campo metodológico para a formação de professores em História: um estudo sobre o PIBID/História/UEL. In: História \& Ensino, Londrina, v. 23, n. 2, p. 11-33, jul./dez. 2017, p. 15.

${ }^{7}$ RAMOS, Márcia Elisa Teté. Op cit, p. 35.

${ }^{8}$ CERRI, Luis Fernando (org.). Os jovens e a história: Brasil e América do Sul. Ponta Grossa: Ed. UEPG, 2018, p. 290-291.

${ }^{9}$ BARCA, Isabel [Org.] Para uma educação de qualidade: Atas da Quarta Jornada de Educação Histórica. Braga, Centro de Investigação em Educação [CIED]/ Instituto de Educação e Psicologia, Universidade do Minho, 2004, p. 132.

${ }^{10}$ BARCA, Isabel [Org.] Para uma educação de qualidade: Atas da Quarta Jornada de Educação Histórica. Braga, Centro de Investigação em Educação [CIED]/ Instituto de Educação e Psicologia, Universidade do Minho, 2004, p. 133.

${ }^{11}$ RAMOS, Márcia Elisa Teté. Op cit, p. 36.

${ }^{12}$ BARCA, Isabel. Ideias chave para a educação histórica: uma busca de (inter)identidades. História Revista, Goiânia, v. 17, n. 1, p. 37- 51, 2012, p. 47.

${ }^{13}$ RAMOS, Márcia Elisa Teté. Op cit, p. 51.

${ }^{14}$ CERRI, Luis Fernando. Ensino de História e consciência histórica. Rio de Janeiro: Editora FGV, 2011, p. 49.

${ }^{15}$ Ibidem, p. 54.

${ }^{16}$ Ibidem, p. 29-30.

${ }^{17}$ RAMOS, Márcia Elisa Teté. Op cit, p. 36.

${ }^{18}$ CERRI, Luis Fernando. Ensino de História e consciência histórica. Rio de Janeiro: Editora FGV, 2011, p. 48.

${ }^{19}$ Ibidem, p. 166.

${ }^{20}$ PEREIRA, Nilton Mullet; SEFFNER, Fernando. Ensino de História: passados vivos e educação em questões sensíveis In: Revista História Hoje, v. 7, nº 13, p. 14-33 - 2018, p. 26.

${ }^{21}$ LEE, Peter. Em direção a um conceito de literacia histórica. Educar em Revista. Ed. Especial. Dossiê: Educação Histórica, Curitiba, p. 131-150, Editora UFPR, 2006, p. 136.

${ }^{22}$ Expressão utilizada por Marc Bloch em sua publicação póstuma: Apologia da História ou O Ofício de Historiador. BLOCH, Marc. Apologia da História ou O Ofício de Historiador. Rio de Janeiro: ed. Zahar, 2001.

${ }^{23}$ KARNAL, Leandro. História na sala de aula: conceitos, práticas e propostas. São Paulo: Contexto, 2010, p. 42.

${ }^{24}$ SCHMIDT, M. A.; CAINELLI, M. Ensinar história. São Paulo: Scipione, 2004, p. 100.

${ }^{25}$ CERRI, Luis Fernando. Ensino de História e consciência histórica. Rio de Janeiro: Editora FGV, 2011, p. 99.

${ }^{26}$ Ibidem, p. 99-103.

${ }^{27}$ Ibidem, p. 122-123.

${ }^{28}$ RAMOS, Márcia Elisa Teté. Op cit, p. 50.

\section{Referências Bibliográficas}

ALBUQUERQUE JÚNIOR, Durval Muniz de. Fazer defeitos nas memórias: para que servem o ensino e a escrita da história? In: GONÇALVES, Márcia de Almeida; ROCHA, Helenice; REZNIK, Luís, MONTEIRO, Ana Maria. (Org.). Qual o valor da história hoje? Rio de Janeiro: Editora FGV, 2012, p. 21-39.

BARCA, Isabel. Aula Oficina: do Projeto à Avaliação. In. BARCA, Isabel [Org.] Para uma educação de qualidade: Atas da Quarta Jornada de Educação Histórica. Braga, Centro de Investigação em Educação [CIED]/ Instituto de Educação e Psicologia, Universidade do Minho, 2004, p. $131-144$. 
BARCA, Isabel. Ideias chave para a educação histórica: uma busca de (inter) identidades. História Revista, Goiânia, v. 17, n. 1, p. 37- 51, 2012. Disponível em: <https://www.revistas.ufg.br/historia/article/view/21683>. Acesso em: 26 jun. 2020.

BLOCH, Marc. Apologia da História ou O Ofício de Historiador. Rio de Janeiro: ed. Zahar, 2001.

CAINELLI, Marlene Rosa; TOMAZINI, Elizabete Cristina de Souza. A Aula-Oficina como campo metodológico para a formação de professores em História: um estudo sobre o PIBID/História/UEL. In: História \& Ensino, Londrina, v. 23, n. 2, p. 11-33, jul./dez. 2017.

CERRI, Luis Fernando (org.). Os jovens e a história: Brasil e América do Sul. Ponta Grossa: Ed. UEPG, 2018.

CERRI, Luis Fernando. Ensino de História e consciência histórica. Rio de Janeiro: Editora FGV, 2011.

KARNAL, Leandro. História na sala de aula: conceitos, práticas e propostas. São Paulo: Contexto, 2010.

LEE, Peter. Em direção a um conceito de literacia histórica. Educar em Revista. Ed. Especial. Dossiê: Educação Histórica, Curitiba, p. 131-150, Editora UFPR, 2006.

PEREIRA, Nilton Mullet; SEFFNER, Fernando. Ensino de História: passados vivos e educação em questões sensíveis In: Revista História Hoje, v. 7, nº 13, p. 14-33 - 2018.

RAMOS, Márcia Elisa Teté. Considerações sobre a construção da história escrita, ensinada e divulgada através da matriz disciplinar de Jörn Rüsen. In. Diálogos. Maringá. v. 22, n. 3. 2018.

SCHMIDT, M. A.; CAINELLI, M. Ensinar história. São Paulo: Scipione, 2004. 